\title{
EL ESTUDIO DE LA CULTURA POLÍTICA: ELEMENTOS PARA UN MARCO TEÓRICO.
}

\author{
William Ortiz Jiménez \\ Facultad de D erecho. D irector G rupo de Investigación: Cultura política y ciudadana
}

RESUMEN: En el presente avance de investigación se exponen elementos determinantes para una interpretación integral en torno a la cultura política. El análisis se centra a partir de la teoría expuesta por Almond y Verba, la Cultura Cívica, la cual establece que los fenómenos históricos, las fundamentaciones, ideológicas y los hechos religiosos son factores esenciales en la conformación de la cultura política. De igual forma, se presentan los aportes realizados desde de la investigación sociológica interpretativa, la cual generó tanto críticas al respecto como desarrollos teóricos al concepto de cultura política.

PALABRAS CLAVE: Cultura política, cultura cívica, democracia, participación ciudadana.

SUMMARY: The present investigation advance exposes decisive elements for an integral interpretation around the political culture. The analysis is centered starting from the theory exposed by Almond and Verba, the Civic Culture, which establish that the historical phenomenon, the ideological foundations and the religious facts are essential factors in the conformation of the political culture. Also, it exposes the contributions from the interpretive sociological investigation, which generated so much critical in this respect as theoretical developments to the concept of political culture.

KEY WORDS: Political culture, civic culture, democracy, civic participation 
La cultura política, en la acepción que trae el diccionario de ciencia política de Alianza Editorial (1998: p. 32), es considerada como un elemento clave del enfoque teórico conductista ${ }^{1}$ por constituir una variable relativamente permanente, que determina el comportamiento político colectivo de un país. El carácter estructural de esta noción le confiere una gran ambición explicativa y, al mismo tiempo, provoca críticas de quienes la usan frecuentemente por pretender aplicar elementos culturales a todo lo que no se puede analizar de otro modo. Los autores clásicos de la cultura política, Almond y Verba, la concibieron como la orientación que los miembros del sistema político desarrollan hacia ellos mismos como partícipes del proceso político, así como hacia algunos elementos del mismo (partidos, grupos de interés e instituciones). Por tal motivo, se configura como un procesamiento psicológico que va sumando sentimientos y conocimientos fundamentales sobre cómo funciona, y debe hacerlo, el poder político. Esta situación incluye tanto actores públicos como privados. Aún, para este caso, se deben tener en cuenta elementos tales como aquellos relacionados con la subcultura, pues la de élite es distinta a la de las masas y aquellas otras relacionadas con la variantes regionales, étnicas y raciales. En la cultura política, por lo tanto, se tienen en cuenta factores capaces de generar creencias sobre el sentido de los objetos políticos, recrear escalas de valores y, finalmente, determinar las conductas políticas de todo un grupo como la memoria colectiva, el conjunto de historias individuales, el desarrollo socioeconómico, el grado de cohesión etnoterritorial o la importancia de la religión.

No desconocieron Almond y Verba, que la cultura política es asimilada por los miembros de una socie- dad a través de un proceso de socialización en el que intervienen las familias, los partidos dominantes, los pares de amigos y los medios de comunicación. Una vez se interioriza, la cultura orienta la reacción ante nuevos estímulos y lo hace de diversas maneras.

Por lo tanto, hacer referencia a la cultura política no es más que aclamar el éxito que tuvo y que aún tiene vigencia, la obra de Almond y Verba: la cultura cívica. Por tal motivo, y para la investigación que nos convoca en torno a la Cultura Política de los aspirantes a los cargos públicos y el público en general del Área Metropolitana de Medellín, es preciso tener en cuenta que una primera parte de esta investigación es una revisión precisa y a profundidad respecto de la obra inicial sobre el estudio de la cultura política que realizaron G. Almond y Sigmund Verba y continuada años después por la corriente de la política comparada u otras que manifiestan interés en este tipo de investigaciones, sobre todo, en las décadas de los años sesenta y setenta en las cuales dominan los estudios europeos y norteamericanos.

En la segunda parte se revisa la contraparte conceptual, es decir, aquellas posturas académicas e investigativas que elaboran una serie de críticas a la propuesta de Almond y Verba, desde la sociología interpretativa y que presenta un enfoque distinto de Cultura Política. Se intenta integrar dos enfoques conceptuales aparentemente irreconciliables: la interpretativa y la comparatista en su versión más reciente $^{2}$. Para tal fin, se recurre a las fuentes bibliográficas e interpretativas, así como a los diversos contextos teóricos expuestos por un gran número de analistas políticos, sociólogos, antropólogos e investigadores frente al tema. Pero, con el fin de no caer

\footnotetext{
${ }^{1}$ Enfoque politológico caracterizado por el estudio del comportamiento observable de los actores políticos a través de investigaciones cuantitativas. Los inicios radican en la Escuela psicológica conductista, que proponía concentrarse en el examen de las reacciones estímulo respuesta y que influyó notablemente en diversas áreas del conocimiento, entre ellas la relacionada con la ciencia política. Se le reconoce la contribución que hizo al auge de la teoría general de sistemas, y al hecho de seguir compartiendo el protagonismo científico con otras corrientes, como la racional choise, el institucionalismo o el análisis de las políticas públicas. Aún continúa aplicando elementos de medición y en su tradicional objeto de estudio incluye la participación y la apatía política, el voto, los partidosy, en esencia, la cultura política.

${ }^{2}$ Según Almond, se trata de la línea psicológica dentro de la tradición del estudio de la cultura política, representada por Wallas, G; Lippman, W; McD ougall y otros (Almond, G. 1990). No obstante su importancia, esa línea de análisis no será revisada en esta primera etapa de la investigación.
} 
en un marco conceptual y un estado del arte demasiado repetitivo, se tomó como fuente principal para esta primera fase de la investigación, esto es, los estudios e investigaciones más reconocidas sobre la cultura política, los aportes que hace la autora Heraz Gómez, en una investigación titulada: Cultura política: el estado del arte contemporáneo. Un texto que contiene un rastreo histórico y un marco teórico bastante amplio referente al tema de cultura política, precisamente, desde la publicación del texto de Almond y Verba y en el cual se da a conocer una síntesis muy centrada al respecto. También se recurre a una serie de investigadores frente al tema, quienes a través de diversos análisis y propuestas, presentan un marco general de la obra de ambos autores y la constriñen al máximo, sin dejar de reconocer el gran aporte que significó y significa para la comunidad académica y la ciencia política en general.

La idea central que presenta Almond y sus seguidores de la misma línea, consiste en que mediante la recuperación del bagaje de representaciones, símbolos e instituciones de una sociedad, estudiadas por la sociología interpretativa, es posible establecer las bases o raíces de la cultura política; pero que ello no es suficiente para explicar las cotidianas percepciones y actitudes de la sociedad hacia la política. Para ello se requiere el estudio comparativo y estadístico, como el que se plantea desde la política comparada. Con ambos, eventualmente, se podrá tener una visión general de la forma en que se percibe y se actúa en términos de lo político en una sociedad determinada.

Con este marco de referencia, una buena dosis de los estudios de la Cultura Política, son abordados por politólogos desde la aparición en 1963 del libro The Civic Culture (Almond, G. and Verba, S.). La ya conocida idea de analizar el comportamiento político en grandes núcleos de la población (Behavioural analysis), utilizando técnicas cuantitativas, fue el núcleo central de una gran parte de las escuelas do- minantes de ciencia política de los años sesenta y setenta y que se constituyó en una escuela de investigación en los Estados Unidos con trascendencia hacia Europa. Poco tiempo después, empieza a recibir las críticas de varias corrientes sociológicas y antropológicas quienes veían en la propuesta de ambos autores, nada más que la prolongación del modelo capitalista norteamericano y europeo, y por presentar una serie de limitaciones en caso de que se considerara el estudio como algo propicio para las otras culturas.

D e no haber sido por la iniciativa de Almond y Verba, quizá no se hubiesen despertado los ánimos para pensar y crear nuevos enfoques de la ciencia política, en especial, los relacionados con la política comparada y el comportamiento político. D esde entonces, surgen autores como R. Inglehart, de la Universidad de Michigan; L. Diamond, de la John Hopkins University; J. Gibbins, apoyado por el E uropean Consortium for Political Research, quienes conforman un grupo académico con importantes avances en el nuevo enfoque de la cultura y participación política de las sociedades contemporáneas ${ }^{3}$. Pero veamos más de cerca las primeras propuestas, para ofrecer un mejor balance de la situación actual.

G ran parte de las investigaciones sobre el tema de la cultura política, como lo expone Heraz Gómez, hasta la última década del siglo XX se llevó a cabo en relación con la obra de G. Almond y S. Verba. Tanto sus críticos como sus apologistas dedicaron varios volúmenes a analizar, sin duda, la considerada obra pionera de la política comparada. A su vez, catalogada como la obra clásica y más influyente en el tratamiento de la Cultura Política, aunque para muchos, después de casi cinco décadas, ya ha sido ampliamente superada.

La obra consistió en un estudio realizado por ambos autores sobre las actitudes de la población hacia sus respectivos sistemas políticos en el cual tomaron

\footnotetext{
${ }^{3}$ HERAZ G Ó MEZ, Leticia. Cultura política: el estado del arte contemporáneo. Reflexión política. Mes de diciembre año 2002. Número 8. Universidad Autónoma de Bucaramanga. P.p. 181-191.
} 
como muestra o países sujetos de análisis, los Estados Unidos, Gran Bretaña, Alemania, Italia y México. Se eligió una muestra de 1.000 habitantes en cada uno de ellos, con el objeto de aplicar un detallado cuestionario que intentaba abarcar tres aspectos de dichas actitudes: los conocimientos sobre el tema político, la identificación del individuo con su sistema político y la evaluación sobre éste; es decir, una dimensión cognoscitiva, una afectiva y una evaluativa o participativa. El estudio considera al sistema político como el lugar en donde se lleva a cabo la asignación autoritaria de valores de acuerdo con los análisis de David Easton y se examina como el centro receptor de demandas más conocidas en el ámbito politológico como inputs y de donde emanan las respuestas, esto es, las outputs. El fin es establecer una imagen-objetivo de democracia frente a la cual se establece la comparación entre países. Una síntesis sobre el estudio se centra en tratar de dar cuenta en qué medida la cultura cívica-política, posibilita el desarrollo de la democracia en un país, pero sobre todo tiende a procurar su estabilidad. D e este modo, Almond y Verba presentan tres tipos de cultura política: parroquial, de súbdito y participativa, e incluyen sus posibles combinaciones. La primera de ellas, se distingue porque los individuos no tienen excesiva conciencia del sistema político en el que están inmersos y, por lo tanto, su participación es insignificante. Hace referencia de manera general a la cultura de algunas comunidades tradicionales apegada a los mitos, a las creencias que no tienen proyecto económico-político. En esta se encuentra una poca o nula conciencia de los sistemas políticos. En cuanto a la de súbdito, se destaca por la existencia de relaciones pasivas en las que se muestra un particular interés hacia los productos políticos del sistema pero no hacia su elaboración. Está relacionada con hechos en los cuales la sociedad tiene cierto grado de participación, de organización con metas u objetivos, pero depende de un líder autoritario. Es aquí, donde los individuos se involucran con los productos del sistema y no con la formulación $\mathrm{y}$ estructuración de las decisiones y políticas públicas y, por último, la cultura valorativa o participativa, está caracterizada por un alto grado de civismo, sí hay articulación entre los ciudadanos y el sistema de elaboración de las políticas de forma que favorece la consolidación democrática. Según Putnam, a mayor grado de vertebración y de implicación de una sociedad en los mecanismos institucionales de decisión, estos aumentan su rendimiento. Este tipo de Cultura política, está enmarcada en lo que los autores observan como una organización entre el individuo y la comunidad, que se sustenta en el poder de elección y que les permite tomar valoración y decisiones frente a las metas u objetivos que se propongan.

Aunque a la final, entienden que el mantenimiento del sistema político democrático está soportado en el desarrollo concreto de la cultura cívica. En otras palabras, la cultura cívica era considerada como aquella que exige de los ciudadanos una participación activa dentro del sistema político, basándose en un cálculo racional e informado y no emocional.

Queda claro que en la obra de ambos autores definen bastante bien las distintas orientaciones que tienen los individuos hacia las estructuras y procesos políticos en el plano cuantitativo, pero quedan muy poco referenciados los apuntes sobre los orígenes 0 el núcleo de la acción política que conlleve a identificar un análisis valorativo o cualitativo. Como investigadores sobre el tema, reconocen que un estudio con estas características: "Tendría que relacionar sistemáticamente tipos de orientaciones de acción política con tipos de estructura social y valores culturales, lo mismo que con los procesos de socialización, con los cuales están relacionados" ${ }^{4}$.

En Cultura Cívica, el eje central, como lo manifiestan implícitamente los autores, no se tenía como ambición central un orden valorativo. Dejan entrever que se trata más bien de un acercamiento a cinco naciones a partir de una particular idea de cultura, de

\footnotetext{
${ }^{4}$ ALMO ND, G., y VERBA, Sigmund (1963). La cultura cívica: actitudes políticas y democracia en cinco naciones. Princeton university press. P. 46 .
} 
política y de democracia, aunque casi todo el desarrollo está centrado específicamente en la variable educativa a través de un enfoque más afín, la psicología, que la misma antropología o sociología. Con base en el desarrollo de la variable educativa, definen la Cultura Política como: "la particular distribución de las pautas de orientación hacia objetos políticos entre los miembros de dicha nación" ${ }^{5}$

En un proceso de revisión y retroalimentación que realizan Almond y otros autores un poco más de veinte años después de publicada Cultura Cívica, encuentran algunas debilidades de esta primera investigación y posterior publicación, pero llegan a la misma conclusión: lo importante fue el haber hecho uso de una metodología de investigación en el ámbito de la ciencia política, en particular el desarrollo de la técnica de encuestas. A partir de esta primera iniciativa se difunden las posibilidades de aplicar encuestas y el método de observación en todos los fenómenos políticos, cuya creciente complejidad rebasaba las teorías existentes. A propósito, Almond dice: "Ahora era posible establecer si existían marcas nacionales distintivas y caracteres nacionales; y en qué medida y grado, se dividían las naciones en subculturas distintivas; si las clases sociales, los grupos funcionales y las élites específicas tenían orientaciones distintivas hacia la política y la política pública y el papel que jugaban los agentes de socialización en el desarrollo de estas orientaciones" ${ }^{\prime \prime}$. En verdad, este parece ser el punto de partida de la preocupación sobre la cultura política, no solamente dentro del campo de la ciencia política sino desde el más amplio de la ciencia social.

A partir de este instante, se consolidan las dos corrientes que han de analizar el desarrollo ulterior de la Cultura Política: la corriente behaviorista y la interpretativa. La primera caracterizada por "...sus aspiraciones científicas libres de valores, por sus tendencias expansionistas y dentro de la investigación de cultura política, por el uso de metodología de apoyo y su 'subjetividad' concomitante o definición psicológica de cultura política" ${ }^{7}$, sin duda, la investigación llevada a cabo contenía un mínimo o bastante impreciso marco teórico sobre el arquetipo de la Cultura Política. Pero fue esencial toda vez que contribuyó a fortalecer el concepto desde otras miradas 0 fortalezas teóricas, en este caso, desde la sociología interpretativa. La cual "...hace uso de las pruebas de plausibilidad y construye la cultura política como significado; es evidentemente omnívora, al contener una definición comprensiva de cultura política" ${ }^{8}$.

Cuando en los postulados de la investigación se hace uso de elementos o hechos comparativos, se remite al propósito exclusivo de la teoría behaviorista, la cual se centra para efecto de sus análisis relacionados con la Cultura Política, en aspectos que tengan correspondencia exclusiva con el comportamiento de los individuos frente a la estructura y proceso político. Los resultados de la investigación son susceptibles de comparación, veamos un ejemplo: al comparar la Cultura Política de distintas naciones, pero también puede ser al comparar sus distintas expresiones a lo largo del tiempo en una misma nación, o bien, al comparar la Cultura Política que se establece desde distintos tipos de regímenes políticos y el uso sociológico de cultura política ${ }^{9}$ y la interpretativa, que propende por conocer los significados, símbolos, códigos de la acción social (la acción política incluida), pero no aspira a una comparación entre culturas. Ya que "entre más detallado y complejo sea el acercamiento a la cultura política, menos comparable puede ser $^{\prime \prime 10}$. La diferencia radica, además de la fundamentación teórica, en el uso que cada una hace en el manejo de la misma.

\footnotetext{
${ }^{5}$ Ibíd., p. 31.

${ }^{6}$ Esta apreciación ocurre después de la revisión de la primera edición de Cultura Cívica en 1963. Paralo cual se consideró el año de 1980. p. 27.

${ }^{7}$ WELCH, S (1993). El concepto de cultura política, St. Martin's Press, New York. P. 6. El texto lo cita Heraz G ómez en inglés.

${ }^{8}$ Ibíd.

${ }^{9}$ Ibíd., p. 7.

${ }^{10}$ Ibíd.
} 
O tro gran contraste entre ambas, esto es, la Cultura Política behaviorista y la Cultura Política interpretativa, se sustenta en la diferencia conceptual respecto a la sociedad. Para los comparatistas, la sociedad podría presentarse como un sistema que tiene funciones y está formado por la suma de individuos en continua y a veces conflictiva relación. Aquí, la Cultura Política sirve como medio para mejorar las reglas de funcionamiento del sistema, a través de un mejor y mayor conocimiento del tipo de régimen político que lo sostiene, pero especialmente por la participación individual que promueve entre los miembros del sistema. La sociología interpretativa tiene otra visión frente a los hechos: en ella, la sociedad no es la suma de individuos, sino las relaciones invisibles que los individuos establecen entre sí y que a lo largo del tiempo forman estructuras e instituciones cuya sedimentación da significado a la acción social, en lo que podríamos llamar una rápida síntesis de la teoría ${ }^{11}$. En este sentido, la Cultura Política forma parte del proceso de estructuración social y se expresa a través de la acción política. Se puede decir que, según esta teoría, la Cultura Política no es diferente a la cultura general, no se tiene una sin la otra, no hay pueblos que tengan Cultura Política sin tener cultura. Para la sociología interpretativa, la Cultura Política no tiene sentido conceptual tal y como está definida en el esquema comparatista.

D e todas formas las críticas más contundentes a la obra de Almond y sus sucesores provienen de la sociología interpretativa. Ejemplo de ello, es cuando afirman que la teoría de Almond niega el papel de las élites dominantes en la difusión de los mitos democráticos y que la cultura cívica y otros estudios de civismo sirven para describir los valores dominantes y, por lo tanto, la teoría finalmente no llega a explicar la estabilidad de los sistemas sociales ${ }^{12}$. En otras palabras se desconoce todo valor explicativo a la obra de Almond y Verba, e incluso se cuestiona severamente el trabajo de los llamados "teóricos empíricos".
Parece ser, que el estudio realizado por Almond y Verba, aunque no fue de una profundidad mayúscula, despertó tanto interés que se le ha exigido mucho más de lo que su contenido estaba en posibilidades de ofrecer. Los mismos autores establecen los alcances conceptuales de la obra, desde el primer capítulo: "Lo que hemos hecho consiste en una serie de experimentos, con el fin de probar algunas de estas hipótesis. Más que inferir las características de una cultura democrática de instituciones políticas o condiciones sociales, hemos intentado especificar su contenido, examinando actitudes en un número determinado de sistemas democráticos en funcionamiento"13 .

Pero, si algo se le ha de reconocer a la investigación de ambos autores, es que la cultura política ha sido muy útil para entender las actitudes de las personas hacia su sistema político, qué saben de él, cómo se identifican con él y cómo lo evalúan. Y con todo ello también es posible comparar distintas orientaciones políticas en las diferentes sociedades. Al menos así lo han entendido los más recientes desarrollos teóricos en esta línea, la cual ha tenido un avance ulterior destacado. Entre ellos, los textos relacionados con la Cultura Política contemporánea, básicos para entender el cambio político en las sociedades posindustriales, sustentado en el paradigma posmodermo, pero con la base sustancial en los estudios comparativos. El texto fue escrito por John R. Gibbins. Luego el de cultura política y democracia en países desarrollados, que ofrece una revisión del desarrollo de la cultura política en el mundo subdesarrollado y algunos países de Europa O riental. Éste, con una perspectiva también de política comparada, que enriquece el legado de Almond, ampliando bastante su panorama analítico, e incluye aspectos culturales decisivos como la religión y otras variables culturales importantes que no fueron contempladas por la multicitada Cultura Cívica.

De hecho, este es ya un nuevo enfoque de cultura política, el cual presenta de manera integral estudios

${ }^{11}$ RITZER, G. (1993), Teoría Sociológica Contemporánea, Mc G raw Hill, Madrid. P. 4.

${ }^{12}$ WELCH, S. (1993), El concepto de cultura política. St. Martin's Press, New York. P.15.

${ }^{13}$ ALMOND, G. (1990). Estudios sobre cultura política. Una disciplina dividida. Sage Publications, London. P. 1970. 
de inferencia estadística sobre cambios de valores en las sociedades contemporáneas. Se trata de investigaciones que ya no observan la fuerte carga ideológica pro-capitalista y de reproducción del sistema democrático liberal estadounidense, pero que sin duda aportan sustanciales hipótesis sobre el cambio sociopolítico de las sociedades contemporáneas.

De estos últimos trabajos de cultura política con fines comparatistas se destacan, por el alcance del programa de investigación en el que se sustenta y por la magnitud de datos que manejan, los aportes de Ronald Inglehart, de la Universidad de Michigan . Este autor comenzó su programa de investigación en política comparada a partir justamente de una reconsideración de los valores culturales como elemento para explicar las diferentes actitudes políticas. En El Renacimiento de la Cultura Política (1988), nos dice: "Las diferentes sociedades se caracterizan en grados muy diferentes por un específico síndrome de actitudes culturales en la política; que éstas diferencias culturales son relativamente perdurables, pero no inmutables con consecuencias políticas mayores, estando altamente ligadas a la viabilidad de las instituciones democráticas" ${ }^{\prime 14}$.

Habría que agregar de paso que la criticada técnica de las encuestas ha superado la fase elemental de recopilación de datos gruesos y superficiales, y ayudada por la inferencia científica aplicada a la investigación cualitativa ${ }^{15}$ es posible ya avanzar notablemente en el terreno de datos finos de grandes poblaciones y proporcionar evidencias de mayor validez a la tarea comparativa.
Hasta aquí lo relativo a la Cultura Política bajo la mirada de la política comparada, pasemos ahora a revisar la propuesta de la sociología interpretativa. Vale la pena, sin embargo, hacer una breve incursión a la teoría de la Elección Racional rational choiœ y ver hasta qué punto sus aportes han sido útiles o importantes en el camino conceptual de la Cultura Política.

Bajo el espectro de la teoría interpretativa, encaminada hacia la racional choise, se asume que todos los individuos llevan a cabo sus decisiones en forma racional, incluidas sus decisiones o elecciones sobre el mundo político. Esta teoría tiene sus raíces en una obra de Gordon Tullock (Chilcote, 1994) ${ }^{16}$, cuya línea es en cierta medida continuada por James Buchanan dentro de la economía y por Anthony Downs por el lado de la sociología y ciencia políti$\mathrm{Ca}^{17}$. En ambos el argumento central es que un análisis del mercado debería estar basado en el individuo racional que persigue sus propios intereses y elige en consecuencia aquello que más le complazca. Una posición netamente individual. En ese sentido la preocupación central era la eficiencia de las instituciones gubernamentales en el diseño de las preferencias individuales sobre los bienes y las políticas públicas.

Pero, sin duda, la obra que marca la decisiva entrada de la Rational Choice a la teoría política es de Mancar Olson, La lógica de la acción colectiva (1992) ${ }^{18}$. En ella el autor hacia los años sesenta y setenta, intentó, basándose en la economía y los modelos formales, describir el ambiente político incluidas las actitudes hacia la política. Almond fue un gran crítico de la misma. La calificaba de reduccionista y en cierto

\footnotetext{
${ }^{14}$ ING LE HART, R (1988). El Renacimiento de la cultura política. En: A merican Political ScienceR eview, December 1988. Vol. 82, Num. 4. p. 1203.

${ }^{15}$ KING, G., KEOHANE, R VERBA, S. (1994). La encuesta en la indagación social, Princeton University Press, New Jersey.

${ }^{16}$ CHILCOTE, RONALD (1994), Teorías de política comparativa. Westview Press, California.

${ }^{17}$ Las obras respectivas son: Buchanan, James (1962), T he Calculus of Consent, Univ. of Michigan, Michigan y D owns. Anthony (1957), A n E conomic Theory of D emocracy, Harper \& Brow, New York.

${ }^{18}$ La edición en español en la editorial Limusa es de 1992, pero la obra original en inglés es de 1965, con el título de The L ogic of Collective A ction: Public $\mathrm{G}$ oods and the theory of $\mathrm{G}$ roups, Cambridge, Mass: Harvard University Press.
} 
modo lo era, para lo cual argumentaba que: "El análisis de la elección racional puede conducir a distorsiones empíricas y normativas, si no es utilizado en combinación con las ciencias históricas, sociológicas, antropológicas y psicológicas, las cuales consideran los valores y servicios de la gente, los intercambios culturales y nacionales, a través de los estratos sociales y en un espacio temporal dado"19.

En gran parte la teoría de la elección racional tiene una muy relativa utilidad si se tratan de buscar significados sobre lo político. Aunque la realidad nos muestra que es poco factible, de acuerdo con todo lo dicho, que un individuo actúe frente al mundo político basado solamente en un cálculo racional individual. Es posible aplicar la teoría, con ciertas reservas, si pensamos en la fase última de la acción política, como podría ser el sufragio; pero la elección racional, carece de un aliciente que sí esgrimieron con suficiente claridad Almond y Verba: los fenómenos históricos, las fundamentaciones, ideológicas, y el hecho religioso, como factores esenciales en la conformación de la cultura política. Todos, sin duda, explican mucho de la Cultura Política de los pueblos.

Esta aproximación teórica es fundamental mencionarla por el gran impacto del mercado en la dinámica social contemporánea, la cual ha agitado el ámbito político en extensa medida. Lo político, en esta consideración teórica, se concibe como un bien público, pero que es susceptible de ser intercambiado en términos del mercado y que los individuos al elegir determinada oferta política, lo hacen en principio eligiendo la mejor del mercado. El meollo del asunto estriba en que de entrada implica la mediación del mercado, con escasas consideraciones históricas 0 ideológicas, religiosas de espacio o tiempo.

El resultado no es más que el de un individuo calculador y frío al momento de elegir políticamente. Por tal motivo, al menos hasta estas reflexiones, parece

\footnotetext{
${ }^{19}$ Almond, op., cit. p. 121.

${ }^{20}$ WELCH, S. (1993). El concepto de cultura política. Op. cit. p.5.

21 Ibíd.
}

difícil encontrar en la teoría de la elección racional una línea de investigación en Cultura Política.

Así que excluyendo la teoría de la elección racional, podemos definir dos grandes campos teóricos a partir de los cuales se ha estudiado la Cultura Política: el comparatista y el interpretativo. El primero -ya esbozado- de la escuela behaviorista cimentando, en buena medida, en el desarrollo de la política comparada. El segundo tiene que ver con varias escuelas teóricas, sobre todo la antropológica y los enfoques sociológicos del interaccionismo simbólico y la fenomenología. Corresponde ahora revisar con mayor detenimiento esta última propuesta.

\section{LA CULTURA POLÍTICA, UNA APROXIMACIÓN DESDE LA IN VESTIGACIÓN INTERPRETATIVA.}

Una vez se pone en marcha cierta patente para iniciar las críticas a la concepción original de cultura política, surgen un conjunto de autores que le apuestan a esta meta y en particular aquellos que representan la tradición en investigación sociológica interpretativa. Esta iniciativa produce una importante fuente teórica, primero por la crítica que ejerce hacia la concepción original del concepto de Cultura Política y, después, como punto de partida de un distinto desarrollo teórico sobre la misma.

Por el lado de la corriente del interaccionismo simbólico y su vertiente de la fenomenología en particular, proveen algunas ideas consistentes para lo que se podrá llamar una teoría interpretativa de la cultura política. En cabeza de Max Weber, pero sobre todo Clifford Geertz, constituyen la mayor influencia en el interpretativismo político-cultural ${ }^{20}$. En el análisis que presenta este enfoque, "dentro de la investigación de la Cultura Política, el rasgo que define la interpretación es un concepto de Cultura Política como "significado" de la vida política, o el aspecto significativo de la política" ${ }^{21}$. 
O bservadas ambas teorías, mientras la corriente behaviorista recurre al criterio de verificación mediante encuestas y estudios empíricos para verificar las teorías, los tratados interpretativos lo hacen con relación a su admisión que ha de conducir a la investigación objeto de la plausibilidad de las mismas.

En la investigación que realiza la sociología interpretativa respecto a la cultura política, presenta dos instrumentos de análisis básicos: el sentido y significado de la acción social. Se sustenta en la idea de que detrás de las acciones de los individuos subyacen ciertos sentidos, lo cual muestra que las acciones de los sujetos no son casuales o meramente accidentales. En el campo de lo político ello significa que las acciones políticas no se sitúan en el nivel superficial, 0 externo, sino que tienen un determinado sentido anterior, un sentido que se va adquiriendo a partir de los usos y costumbres de la comunidad. La acumulación de tal sentido crea significaciones entre los miembros de la comunidad que a su vez se reproducen y forman códigos intersubjetivos. En la formulación teórica todo parece muy claro, pero el problema de investigación aquí es llegar hasta esos códigos y para esto la técnica de las encuestas a grandes poblaciones no es útil. "Los significados intersubjetivos (de una sociedad) deben distinguirse de las actitudes comunes (de esa sociedad), que son las que la técnica de las encuestas es capaz de exponer"22.

Sin dar muchas vueltas hay que ir al grano: las consideraciones teóricas anteriores tienen su origen en la obra de Alfred Schutz más conocida como la fenomenología del mundo social, publicada en 1972. En esta obra el autor centra la atención fenomenológica hacia el campo de lo social, esto es, que el problema no es ahora la explicación del proceso mediante el cual los elementos de experiencia perceptual son entendidos como objetos, distancias y movimientos distintos, sino que se remite hacia una filosofía que atribuye significado y forma a la experiencia humana. Para lo cual agrega Ritzer, que las personas desarrollan y usan 'tipificaciones' en el mundo social. En cualquier situación que se da en el mundo de la vida cotidiana, una acción viene determinada por un tipo constituido de experiencias anteriores ${ }^{23}$.

Ahora los individuos no mantienen una relación de costumbres, tradición, valores y creencias, frente al sistema político, como bien lo postula la formulación clásica con respecto a la Cultura Política, sino que en su lugar, las tipificaciones, resultado de los hábitos y patrones construidos previamente, las utiliza el individuo en su acción social cotidiana y se convierten en instituciones. Así, que la búsqueda por el origen de las prácticas políticas tiene que ver con esos hábitos, patrones, tipificaciones e instituciones. Al hablar, entonces, de la teoría social fenomenológica, se hace alusión a uno de sus postulados centrales: la intersubjetividad como origen de la acción social, siguiendo a Shultz. Continuando con este análisis, el origen de las prácticas políticas de los individuos se ha de situar en el plano intersubjetivo, referido a la forma en que los miembros de una colectividad piensan lo que piensan en relación con lo político.

De manera más concreta, si se retoman los conceptos del enfoque interpretativo aplicados a la Cultura Política, se llega a la siguiente deducción: para conocer el sentido de la acción política se deben interpretar los códigos a través de los cuales se dan las relaciones entre individuos, propias y distintivas a cada grupo social. Y, para descodificar, es preciso reconocer el significado de esos códigos. En esta labor se habrá de buscar el sedimento o la estructura del bagaje común de los sentidos propio del grupo social en estudio o sea el acervo social del que los miembros de dicho grupo echan mano a la hora de actuar.

La pretensión de esta corriente no es más que ampliar el espectro de análisis en lo que se refiere al individuo, considerado en sus mecanismos de con-

\footnotetext{
${ }^{22}$ Ibíd.

${ }^{23}$ RITZER, G. (1993), Teoría Sociológica Contemporánea, O p. Cit. Pp. 268-269.
} 
ciencia, significación, simbología y cosmovisiones como individuo que "hace" la sociedad. Dichas acciones individuales, como acciones sociales, poseen ciertos significados, que a su vez provienen de un depósito común de sentidos, compartidos por los integrantes del grupo social.

En otro contexto, son ideas o nociones que se han fijado de generación en generación y de las cuales se apropian los miembros de una comunidad para responder a las situaciones cotidianas. El cúmulo de significados y sentidos que los individuos le dieron y le siguen dando a sus acciones forma una tradición, la tradición de los sentidos que es compartida por todos los miembros de la comunidad y fuente de la acción social de estos.

Y, aunque dichos sentidos parten del ámbito subjetivo, es muy importante identificarlos, toda vez que permiten averiguar por qué las personas responden de X o Y manera en ciertos momentos o ante problemas determinados; en este caso, por qué responden de tal modo en el mundo de lo político. Las ideas fuertes en esta corriente son: sentido, significado, código, acervo e interpretación.

Siguiendo a Crespi ${ }^{24}$, se ha de observar, que tanto el sentido como el significado de la acción social son todavía muy generales para comprender la acción política, en virtud de que abarcan todo el espacio de lo social, en contraste, el campo de lo político es en principio más restringido, aún si se le considera como el espacio donde tienen lugar la toma de decisiones entre individuos. De manera que el sentido de la acción política se podría empezar a buscar ya en el acervo social o en sistemas de significado de lo político para los miembros de una sociedad los cuales, en palabras de Crespi, "...habiéndose formado a través de la experiencia individual y colectiva, median simbólicamente en las relaciones del sujeto con sí mismo, en las relaciones entre los actores sociales, ade- más de las relaciones entre estos últimos y las condiciones materiales de su ambiente de vida".

En relación con lo anterior, la cultura política es parte del individuo en su vida cotidiana. Subsiguientemente, la acción política de los individuos no está siempre orientada desde las estructuras de poder externas, sino que responde y es objetivación del conjunto de ideas sobre la autoridad y el poder que están contenidas en el acervo social y que se fueron sedimentando históricamente en él. Las consideraciones que los hombres hacen a sí mismos y con los otros hombres sobre la autoridad y el poder en el grupo social, se obtienen principalmente de dicho acervo, pueden cambiar y se pueden negociar en cada acción política, pero una buena parte se preserva y hereda. En otras palabras, lo político no se encuentra en el sentido inmediato de la acción social, no es tan esencial, tan próximo al individuo, se sedimenta paulatinamente y puede objetivarse 0 no en acción política. De ahí que todo individuo, aún sin reconocerlo, tenga un acervo cultural de lo político. Es decir, tenga una determinada Cultura Política, aún haciéndola objetiva $0 \mathrm{no}^{25}$.

La reproducción del orden político está supeditada a la fuerza que posea el acervo, esto significa que son las acciones individuales de los hombres quienes lo hacen, es su acto cotidiano el mecanismo de preservación de dicho orden; siendo, al mismo tiempo, la acción individual la que puede cambiarlo, este argumento teórico, viene dado por todos los representantes de la fenomenología, lo cual lleva a interpretar que en cada acción individual se negocia el orden vigente. ¿Qué da a entender lo anterior? Pues, que la cultura política no está dada para siempre, sino que una parte la reproducen los hombres y otra se negocia y cambia. Esta es una forma de entender tanto la cultura política como el cambio político, a través del análisis de las acciones individuales.

\footnotetext{
${ }^{24}$ CRE SPI, F. (1997). Acontecimiento y estructura. Buenos Aires: Edición Nueva Visión, P. 12.

${ }^{25}$ HERAZ G Ó MEZ, Leticia. Cultura política: el estado del arte contemporáneo. Reflexión política. O p. Cit. P. 195.
} 
El individuo, en este marco de reflexión, está puesto en toda su amplitud social, por lo tanto, sus acciones tienen un fuerte ingrediente subjetivo que se debe rastrear en la tradición de los sentidos de la comunidad objeto de estudio, partiendo de la consideración de que la subjetividad de los agentes sociales es intersubjetiva cuando aflora y se objetiva ante los otros, formando de este modo verdaderos códigos intersubjetivos. Y si se quiere ir más al fondo, es necesario acudir a la memoria, la percepción e imaginación de los individuos, es decir, en su conciencia social, para saber cómo han construido dicha tradición de sentidos, aquí referida al tema de lo político ${ }^{26}$.

Luego, la función consiste en descodificar la cadena de significados, para una precisa interpretación. Puesto que según el grupo social o etapa de análisis, los códigos intersubjetivos llegan a ser demasiado complejos y una mirada superficial no da pistas sólidas para la tarea interpretativa, punto al que el investigador quiere llegar. En este enfoque, es del entramado intersubjetivo de donde provienen las prácticas políticas de determinada comunidad o grupo social.

A hora bien, la acción política no empieza con la consideración del hombre como miembro de una comunidad política, porque con anterioridad se han formado la mayor parte de los códigos intersubjetivos con los que se actúa en la vida política. Sino, que según Heraz Gómez, su conjunto permite que se conformen estructuras históricas específicas de depósitos sociales de sentido, dentro de las cuales una parte del acervo es accesible a todos, como conocimiento de sentido común, y otra corresponde al conocimiento especializado de acceso restringido. Es justamente con el conocimiento general de sentido común con el que el individuo responde políticamente, pero ante contingencias desconocidas, es decir ante acontecimientos que no se encuentran en su acervo y a los que no sabe responder, busca con mayor 0 menor éxito el conocimiento de los especialistas.

Si existe, existe interés para la realización de una investigación sobre el origen de la cultura política tomando como punto de partida los elementos de este enfoque, se debe averiguar primero, la estructura histórica específica de los depósitos de sentidos y cuáles han sido las relaciones dominantes, y luego, ir descodificando los códigos intersubjetivos relevantes en la comunidad objeto de estudio. La interpretación de éstos constituye el paso final.

El enfoque es muy interesante, pero quizá resulta notoriamente difícil recuperar el nivel de análisis que demandaría la cultura política en grandes poblaciones, porque el rastreo conceptual y la descodificación tendría un mayor desarrollo en grupos muy pequeños 0 incluso a individuos. Retomando las palabras de Hannah Arendt, la política está referida a los asuntos públicos y hablar de política es hablar de pluralidad $^{27}$, entonces lo político es ante todo un concepto que busca estudiar asuntos que relacionan a los individuos en torno a un orden público. En este sentido la sociología interpretativa tiene sus límites.

Pero no se puede dejar perder el hilo conductor y tratar de arriesgar una definición de Cultura Política bajo esta mirada, la cual podrá ser: la cultura política es el acervo de códigos que los hombres han construido históricamente acerca de su orden político vigente. Y la acción política es la objetivación de dicha cultura. Para efectos de la investigación hay, entonces, una tarea de por medio: comenzar con el estudio del grupo social de manera que se puedan emprender las indagaciones sobre su particular acervo social y deslindar de éste los códigos mediante los cuales los individuos objetivan su cultura política.

${ }^{26}$ Ibíd.

${ }^{27}$ ARENDT, G. (1997), ¿Q uées la política?, Paidós, Barcelona. P. 3. 


\section{A MANERA DE CONCLUSIÓN}

Una vez surge el término relacionado con la Cultura Política y los continuos debates en torno a su significado y posibles aplicaciones, se abre el espacio para impulsar en grado sumo, la concepción relacionada con la ciencia política. A pesar de lo controvertido del concepto, la Cultura Política ha sido germen de crecimiento de diversas corrientes relacionadas con la ciencia política. Quizá, esta fuerza se debe a que su interés no sólo se sustenta en la fuente sociológica, sino en la antropológica, la económica, la filosófica y muchas otras disciplinas de las ciencias sociales. Aunque los dos campos teóricos desde los cuales se ha abordado la investigación están constituidos por la política comparada y la sociología interpretativa, existe en la actualidad una gran producción teórica que apunta en una dirección mucho más comprensiva en lo concerniente con el cambio de valores de la sociedad contemporánea.

D e manera indiscutible, el legado de Almond ha rendido frutos, a tal punto que permitió afinar y quizá constituir desde la década de los noventa una nueva línea de investigación politológica: la relacionada con el cambio de valores en sociedades en transición 0 entre sociedades 0 también sobre diferentes etapas transcurridas al interior de una sociedad. El paradigma etnocentrista del proyecto de Almond, se ha empezado a abandonar.

Cuando se pregona, de manera un poco pesimista, la muerte lenta de la teoría de Almond y Verba, no es porque ya esté en desuso. Resulta, que revisada la literatura sobre los estudios de carácter interpretativo, se encontró que tienen bastante qué decir en el ámbito de la Cultura Política. Y, que hoy, constituyen, en muchos sentidos, la base analítica sobre la que ha de sustentarse toda pretensión investigativa relacionada con la Cultura Política desde el ámbito comparativo. Es más, es la acción política, pero también el sentido de la acción política, lo que debería contener una investigación en Cultura Política.

Hemos visto cómo el viejo contenido conceptual de cultura política se ha enriquecido. La cultura no es únicamente lo ya sedimentado en y por una sociedad, sino que constituye un proceso en el cual la Cultura Política hace referencia precisamente a los aspectos políticos (Welch, 1993: 164); bien merece la pena abordar el tema.

Para efectos de la investigación propuesta como estudio de caso en referencia al grado de Cultura Política que poseen los aspirantes al concejo, a las alcaldías y público comprometido con la política participativa, bajo esta doble mirada teórica es factible hacer aproximaciones que permitan explicar, entender, y analizar la cultura y la participación política de diversos actores en múltiples etapas, y además arriesgar algunas comparaciones.

La cuestión para el presente marco teórico no es más que la siguiente: hacer uso de la sociología interpretativa que conlleve a la recuperación histórica de los valores político culturales de una sociedad y elaborar un mapa teórico de la cultura política hasta el presente, sustentado a partir de la política comparada con base en los estudios de Almond y Verba.

De otra parte, todo el esquema presentado en marco teórico hace posible analizar de manera conjunta cultura y la participación política en términos de proceso de investigación. Esto es, procurar las bases histórico-político-culturales que permitan articular luego, sobre éstas las formas de participación política en el contexto urbano del área metropolitana de la ciudad de Medellín. La triangulación teórica, da respuesta a la idea de que la cultura produce las actitudes y que difícilmente se explican independientes. En síntesis: a toda actitud política corresponde una pauta cultural previa. Veamos un ejemplo: votar no es acto casual, sino que responde a un esquema de valores sedimentado en el grupo social bajo estudio. Participar en manifestaciones, protestas, marchas, mítines, entre otras, no son acciones sin sentido, son el producto de pautas establecidas de un comportamiento político cimentado históricamente. La intención es entonces, constituir una nueva forma de investigar en el ámbito de la Cultura Política. 
El estudio de la Cultura Política: Elementos para un marco teórico.

\section{BIBLIOGRAFÍA}

ALMOND, Gabriel y VERBA, Sidney. La cultura cívica. Princeton: University Press, 1963.

ALMO ND, G. AND VERBA, S (1963), The Civic Culture: Political A ttitudes and D emocracy in Five Nations, Princeton, NJ: Princeton University Press.

( 1980), The Political Culture Revisited, Little Brown, Stanford.

ALMOND, G. (1990), "The Study of Political Culture" en A D iscipline D ivided, Sage Publications, London. ARENDT, G. (1997), ¿Q ué es la política?, Paidós, Barcelona.

BERGER,L. P. y LUCKMAN T. (1995), M odernismo, pluralismo y crisis de sentido, Paidós, Buenos Aires.

CHILCOTE, RONALD (1994), Teorías de política omparativa. Westview Press, California.

CORTINA, Adela. Ciudadanos del Mundo. Alianza Editorial, Madrid. 1997.

CRESPI, F. (1997). Acontecimiento y Estructura, Edición. Nueva Visión, Buenos Aires.

D IAMO ND, L. (1989), Cultura política y cambio democrátioo en las ciudades, Lynne Riemer Pub. London.

EASTON, D. (1965), E squema para el A nálisis Polítion, Amorrortu Edit., Buenos Aires.

GEERTZ, C. (1995), La interpretación de las culturas, Gedisa, Barcelona.

G IBBINS, J. (1989), Contemporary Political Culture, Politics in a M odern A ge, Sage Publications, Londres.

HERRERA CORTÉS, Marta Cecilia, PINILLA DÍAZ, Alexis V., et al. La construcción de la cultura política

en Colombia: proyectos hegemónicos y resistencias culturales. Bogotá: Plaza \& Janés, 2005.

HERRERA CORTÉS, Martha Cecilia y D ÍAZ SOLER, Carlos Jilmar. Educación y cultura política: una mirada interdiscplinaria. Bogotá: Plaza \& Janés, 2001. 382 p.

ING LEHART, R. (1988), El Renacimiento de la cultura política. en A merican Political Science Review, D ecember 1988. Vol. 82, Núm. 4.

ING LEHART, R. (1997). Modernización y Postmodernización. Princeton U J, Princeton University Press.

INSTITUTO POPULAR DE CAPACITACIÓN IPC. Cultura ciudadana y comportamiento político-electoral en Medellín: una síntesis (1997-2003). Medellín: 2005.

KING, G., KEOHANE, R VERBA, S. (1994), La encuesta en la indagación social. Princeton University Press, New Jersey.

LAND MANN, T. (2000). Issues and Methods in Comparative Politics, Routlegde, Londres.

LONDOÑO ÁLVAREZ, Orlando. Análisis de la participación político electoral de la comuna 4 de la zona nororiental del municipio de Medellín en octubre 29 del año 2000 (trabajo de grado para optar al título de Sociólogo). Medellín: Universidad Autónoma Latinoamericana, 2002.

MARSHALL, T. Ciudadanía y Clase Social. En: Revista Española de Investigaciones Sociológicas. №. 79. Jul-Sep/ 1997.

MURRAY, Edelman. La construcción del espectáculo político. Buenos Aires. 2002.

MURRAY, F. (1994), Algunos problemas metodológicos en políticas comparativas. En: Journal of Theoretical Politics, Vol. 6 (3), Sage Publications, Londres.

O LSO N, M. (1992), L a lógica de la acción colectiva: bienes públioos y la teoría de grupos, Limusa, México.

PUERTA LÓ PEZ, Uber; PÉREZ MÚNERA, Carlos Andrés; et al. La participación ciudadana y el desarrollo de la cultura política en Colombia. Bogotá: Legis, 2006. 136 p.

RITZER, G. (1993), Teoría Sociológica Contemporánea, Mc G raw Hill, Madrid.

RIVERO, Ángel. Ciudadanía y republicanismo: un acercamiento contemporáneo. Colección Pensamiento Político Contemporáneo № 10. Medellín: Universidad Pontificia Bolivariana, 2005.

SCHUTZ, A. (1972), Fenomenología del mundo social, Paidós, Buenos Aires.

UNIVERSIDAD NACIONAL DE COLO MBIA. Facultad de D erecho. G rupo de investigación Cultura Política y Poder Constituyente en Colombia. Cultura política, ciudadanía y democracia. Bogotá: Guadalupe, 2005. 95 p. 
Ratio Juris

UPAZO MARMENTINI, Juan. Ciudadanía y D emocracia. Una Mirada D esde las Ciencias Sociales. En: Metapolítica. México. Vol.4. Jul-Sep/ 2000.

VARGAS VELÁ SQUEZ, Alejo. D emocracia, Crisis Política y G obernabilidad. En: D emocracia y Crisis Política, Universidad Nacional de Colombia, № 23, Bogotá, 1996.

WELCH, S. (1993), El concepto de cultura política. St. Martin's Press, New York. 